\title{
Effect of low dose aspirin on maternal outcome in women at risk for developing pregnancy induced hypertension
}

\author{
Madhusmita Pradhan ${ }^{1}$, Kishore S. V. ${ }^{2}$, Jyotiranjan Champatiray ${ }^{3 *}$
}

\author{
${ }^{1}$ Department of Obstetrics and Gynecology, ${ }^{2}$ Department of Pediatrics, SCB Medical College and Hospital, Cuttack, \\ Odisha, India \\ ${ }^{3}$ Department of Pediatrics, SVPPGIP, SCB Medical College and Hospital, Cuttack, Odisha, India
}

Received: 23 January 2020

Accepted: 28 February 2020

\section{*Correspondence:}

Dr. Jyotiranjan Champatiray,

E-mail: jrcray@rediffmail.com

Copyright: (C) the author(s), publisher and licensee Medip Academy. This is an open-access article distributed under the terms of the Creative Commons Attribution Non-Commercial License, which permits unrestricted non-commercial use, distribution, and reproduction in any medium, provided the original work is properly cited.

\begin{abstract}
Background: Pre-eclampsia is not totally a preventable disease. It is found more related to chains of social ills such as poor maternal nutrition, limited or no antenatal care and poor reproductive education. However, some specific "high-risk" factors leading to pregnancy induced hypertension (PIH) may be identified in individuals which include and not limited to young and elderly primigravida, multiple pregnancy, diabetes, Rh incompatibility, new paternity, pre-existing vascular or renal disease, family history of hypertension, pre-eclampsia and eclampsia, obesity, thrombophilia. Low dose aspirin given in $2^{\text {nd }}$ trimester in these high-risk women is anticipated to prevent the development of PIH.

Methods: This prospective randomized controlled trial was conducted in the department of obstetrics and gynecology, SCB MC and Hospital, Cuttack during November 2018 to October 2019. Pregnant women between the gestational age of $13^{\text {th }}$ to $28^{\text {th }}$ weeks were screened for risk factors and included in this study. Low dose aspirin of 60 $\mathrm{mg}$ daily till delivery was given to pregnant women who consented to be a part of study randomly with the other group having placebo.

Results: Protienuric hypertension was high in control group who did not receive aspirin. Low dose aspirin significantly reduces $\mathrm{PIH}$ in high-risk group (3.48\% in case versus $23.52 \%$ in control). Low dose aspirin was not associated with significant increase in placental bleeding. Low dose aspirin was generally safe for the fetus and new born infant with no evidence of an increased likelihood of bleeding.

Conclusions: Low dose aspirin has a definite role in the prevention of PIH in high risk pregnancy. Low dose aspirin reduces the incidence of $\mathrm{PIH}$. Low dose aspirin can be considered a safe drug without any deleterious side effect for mother and the fetus. Benefits of prevention of $\mathrm{PIH}$, justifies its administration in women at high risk.
\end{abstract}

Keywords: Aspirin, High risk pregnancy, Pre-eclampsia, Thromboxane

\section{INTRODUCTION}

Hypertension in pregnancy is a predominant cause of intrauterine growth retardation, intrauterine asphyxia, neonatal and maternal morbidity and mortality. In spite of all the advances made in medical science, pregnancy induced hypertension (PIH) continues to be responsible for a high proportion of hospital admission, labor induction, maternal and fetal morbidity and mortality.

Even in advanced countries where other complications like hemorrhage and sepsis have been either completely or partially resolved, PIH still remains the most common cause of maternal mortality. ${ }^{1}$ However, in India severe 
$\mathrm{PIH}$ is the third major killer of pregnant women behind hemorrhage and sepsis. ${ }^{2}$ In a recent review of causes of maternal deaths from different parts of India, it has been observed that hypertensive disorders of pregnancy accounts for $7-8 \%$ of all maternal deaths. ${ }^{3}$

Although "toxemia of pregnancy" is known to the obstetricians right from the time of Hippocrates, its exact pathogenesis remains obscure till date. It is unpredictable, multi-organ disorder unique to human pregnancy. It typically occurs in $2^{\text {nd }}$ and $3^{\text {rd }}$ trimester of pregnancy with usual clinical manifestations of hypertension, proteinuria, oedema and central nervous system irritability. If early detection and treatment is not don, eclamptic convulsion with its complications may occur. Hence timely detection and prompt management in the early stages of the disease by thorough antenatal check-up is of paramount importance.

Pre-eclampsia originates in the placenta, probably as the result of under-perfusion of the uteroplacental circulation associated with structural and occlusive changes in the spiral arteries. ${ }^{4}$ One of the mechanisms suggested includes enhanced sensitivity to vasopressors, an abnormal maternal immunologic reaction and imbalance in the production of vasoactive prostaglandins [thromboxane $\mathrm{A}_{2} \quad\left(\mathrm{TXA}_{2}\right)$ and prostacyclin $\left(\mathrm{PGI}_{2}\right)$ ] resulting in vasoconstriction of small arteries, platelet activation and uteroplacental insufficiency.

Both $\mathrm{TXA}_{2}$ and $\mathrm{PGI}_{2}$ are derived from arachidonic acid through the action of the enzyme cyclo-oxygenase. When compared with normal pregnancy, endothelial PGI2 production is decreased in pre-eclampsia. At the same time, $\mathrm{TXA}_{2}$ secretion by platelet is increased. Hence $\mathrm{PGI}_{2}: \mathrm{TXA}_{2}$ ratio decreases, resulting in vasoconstriction as $\mathrm{TXA}_{2}$ is a potent vasoconstrictor.

The low dose aspirin (60 $\mathrm{mg}$ to $100 \mathrm{mg}$ daily) by acetylation, selectively inhibits the synthesis of platelet $\mathrm{TXA}_{2}$ without affecting the endothelial derived $\mathrm{PGI}_{2}$. This selective inhibition of platelet thromboxane production is the basis for attempts to prevent the development of PIH with low dose aspirin. Low dose aspirin during $2^{\text {nd }}$ trimester reduces the risk of PIH and improves pregnancy outcome. ${ }^{5}$

\section{METHODS}

The present study was conducted on 240 pregnant women visiting the antenatal clinic of department of obstetrics and gynecology, of SCB Medical College and Hospital, Cuttack between November 2018 to October 2019. Amongst the 240 only 203 patients could be followed up till delivery. This was a prospective randomized control trial, which was single blinded. Study was conducted after the approval of Institutional Ethical Committee. Pregnant women between 13 to 28 weeks of gestation were screened for risk factors for development of PIH were included.

\section{Inclusion criteria}

- $\quad$ Aged $\geq 18$ and $<55$ years

- Live foetus at gestational age 12-20 weeks

- Be at high risk of developing pre-eclampsia based on clinical risk factors such as the following:

a. At least one high-risk factor, namely history of pre-eclampsia, diabetes mellitus (type 1 or 2 ) or chronic hypertension.

b. At least two intermediate-risk factors, including obesity $\left(\geq 28 \mathrm{~kg} / \mathrm{m}^{2}\right)$, young primigravida $(<20$ years) advanced maternal age ( $\geq 35$ years), family history of pre-eclampsia (mother and/or sister) or nulliparity.

- $\quad$ Able to provide written informed consent.

\section{Exclusion criteria}

- Allergic to aspirin

- Asthma

- Peptic ulcers

- Severe heart, liver or renal disease

- Those not consented to be part of study

- Previous or present $\mathrm{h} / \mathrm{o}$ bleeding diathesis.

These women were divided into 4 groups

- $\quad$ Group A- women with low platelet count (1 lakh-1.5 lakh/ $\mathrm{mm}^{3}$ ) treated with aspirin $60 \mathrm{mg}$ daily from date of enrolment till deliver

- Group B- women with low platelet count without aspirin on placebo

- Group C- women with risk factors treated with aspirin $60 \mathrm{mg}$ daily from date of enrolment till delivery

- Group D- without with risk factor without aspirin therapy on placebo.

These patients were followed up at 4 weeks interval up to 28 weeks, at 2 weeks interval up to 36 weeks and thereafter at weekly interval till delivery. At each visit weight gain, pedal oedema and blood pressure Urine albumin and total platelet count was done at the time of enrolment. Urine albumin was repeated at 28-32 weeks, 32-36 weeks and 36-40 weeks, or when features of preeclampsia developed. At delivery gestational age, fetal maturity, fetal birth weight, fetal and neonatal mortality and morbidity and fetal congenital abnormalities were recorded. Any neonatal bleeding or maternal adverse effects like abruptio and post-partum hemorrhage was also noted. The result was subjected to statistical analysis using SPSS 23.0 version. To describe about the data, descriptive statistics, frequency analysis, percentage analysis were used for categorical variables and for continuous variables the mean and SD were used. To find the significant difference between the bivariate samples in independent groups, the independent $t$ test was used. To find the significance in categorical data, Chi-Square test was used. In all the above statistical tools, the 
probability value of $<0.05$ was considered as significant level.

\section{Randomization}

Randomization was performed using a computerized central randomization system in a 1:1 allocation ratio. The website randomly assigns a randomization code to each participant. Eligible women will be randomized to one of the two groups. Knowledge of the treatment allocation is open to the investigators and the participants. Those with low platelet count are separated into a separate group.

\section{RESULTS}

In this study there were initially 240 cases recruited and among them only 203 cases could be followed up till delivery. Out of 240 cases $41.67 \%$ were from age group of 21-25years, 35\% were from $26-30$ years, $11.25 \%$ from $31-35$ years, $8.33 \%$ were below 20 years and $3.75 \%$ were equal to or more than 35 years. Maximum patients were between 21-25 years and least were elderly gravidae (Figure 1).

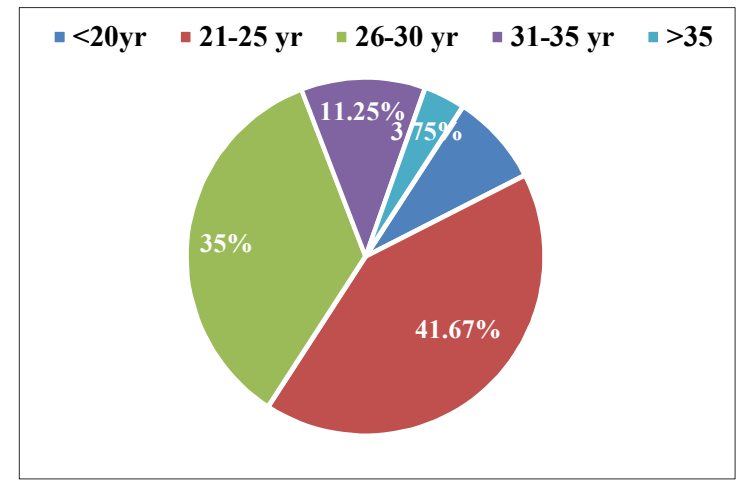

Figure 1: Distribution of cases according to age.

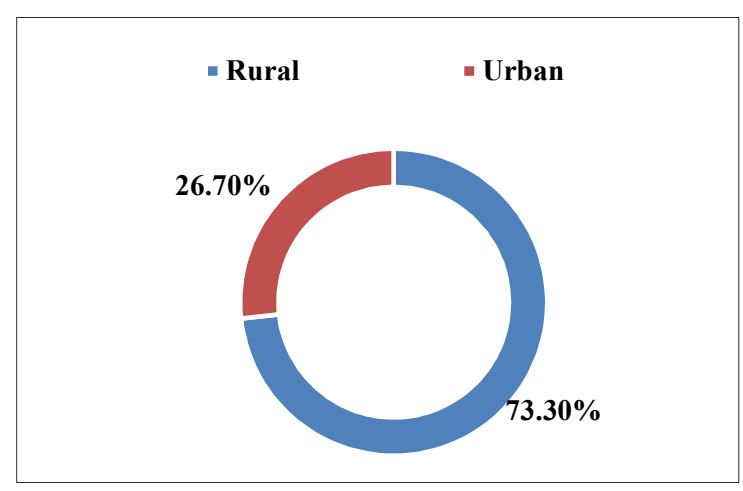

Figure 2: Habitation of study cases.

In this study population $73.3 \%$ of the cases were from rural domicile whereas $26.7 \%$ were from urban background (Figure 2). 5\% were from upper class according to modified Kuppuswamy classification. $60 \%$ were from middle class and 35\% were from lower class according to modified Kuppuswamy classification (Table 1).

Table 1: Distribution of cases according to socioeconomic status.

\begin{tabular}{|lll|}
\hline Socio economic status & No. of cases & Percentage \\
\hline Upper & 12 & $5 \%$ \\
\hline Middle & 144 & $60 \%$ \\
\hline Lower & 84 & $35 \%$ \\
\hline Total & 240 & $100 \%$ \\
\hline
\end{tabular}

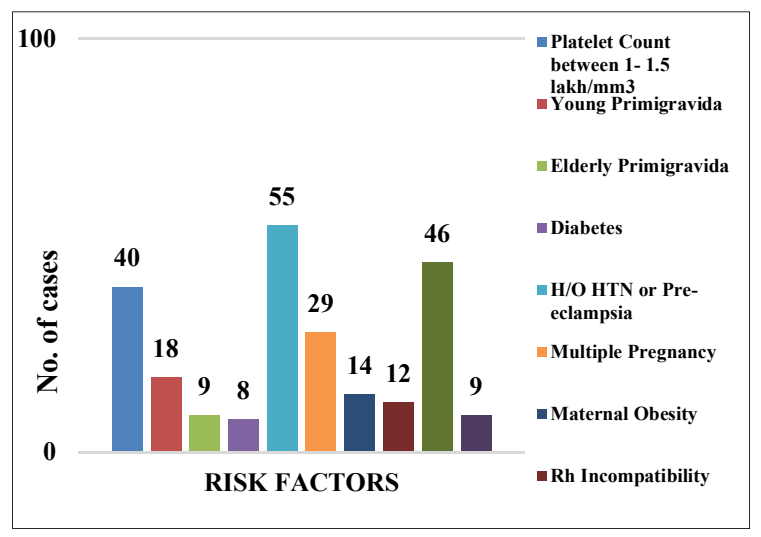

Figure 3: Distribution of cases as per risk factors.

If we look into the distribution of risk factors in the study population $16.6 \%$ had low platelet count i.e. between 1 $1.5 \mathrm{lakh} / \mathrm{mm}^{3}$. This group was studied separately in this study. $7.5 \%$ were young primigravidae, $3.8 \%$ were elderly primigravida, $3.4 \%$ were diagnosed with diabetes at the time of enrolment in this study. History of previous pregnancy complicated by pre-eclampsia were $22.9 \%$ which formed the majority of the study population. $12.1 \%$ were multiple pregnancy, $5.8 \%$ were having maternal obesity with BMI $>\geq 28 \mathrm{~kg} / \mathrm{m}^{2}, 5 \%$ had Rh incompatibility and $19.2 \%$ had previous still birth or abortions in previous pregnancy. 3.7\% had chronic hypertension Figure 3.

Table 2, compares the characteristics two groups that is the aspirin and the placebo group at the time of registration into the study. As is evident from the table there is no significant difference in regard to maternal age, weight, blood pressure, platelet count and presence of urine albumin. Hence the above two groups can be statistically comparable to each other.

When comparison of severity of PIH in studied groups as per gestational age was studied only 2 cases in Group D (i.e. women with risk factors not on aspirin) developed $\mathrm{PIH}$ between 28-32 weeks of gestation. There were no cases in aspirin treated groups. The same Group D had 9 mild PIH cases during the gestation period of 33-36 weeks and one severe PIH. By the time of more than 36 weeks of gestation Group D had 7 cases of mild PIH and 
2 cases of moderate PIH and 2 cases of severe PIH. Also, there was 1 each case of mild and moderate PIH in Group B, Table 3 .
When the incidence of PIH at the time of delivery was analysed in this study found that incidence of PIH in aspirin treated group was $3.8 \%$ and placebo treated group had an incidence of PIH at $18.8 \%$ Table 4.

Table 2: Clinical characteristics of different cases at initial visit.

\begin{tabular}{|c|c|c|c|c|c|}
\hline \multirow{2}{*}{\multicolumn{2}{|c|}{ Clinical characters }} & \multicolumn{2}{|l|}{ Aspirin } & \multicolumn{2}{|c|}{ Placebo } \\
\hline & & Mean & SD & Mean & SD \\
\hline Age in years & & 26.12 & 4.93 & 25.28 & 4.66 \\
\hline Weight in $\mathrm{kg}$ & & 48.42 & 7.66 & 48.20 & 7.94 \\
\hline Diastolic BP in $\mathrm{mml}$ & & 74.92 & 5.58 & 75.3 & 7.86 \\
\hline Systolic BP in $\mathrm{mmH}$ & & 114.5 & 9.20 & 117.25 & 12.98 \\
\hline \multirow{2}{*}{$\begin{array}{l}\text { Total platelet count } \\
\left(\text { lakhs } / \mathrm{mm}^{3}\right)\end{array}$} & High risk (other than low platelet) & 2.22 & 0.24 & 2.21 & 0.3 \\
\hline & Low platelet count cases & 1.31 & 0.08 & 1.36 & 0.05 \\
\hline \multicolumn{2}{|l|}{ Urine albumin } & Absent & & Absent & \\
\hline \multicolumn{2}{|l|}{ Pedal oedema } & Absent & & Absent & \\
\hline
\end{tabular}

Table 3: Comparison of severity of PIH in studied group as per gestation age.

\begin{tabular}{|c|c|c|c|c|c|}
\hline G.A. in weeks & Type of PIH & Group A & Group B & Group C & Group D \\
\hline \multirow{3}{*}{$28-32$} & Mild & Nil & Nil & Nil & 2 \\
\hline & Moderate & Nil & Nil & Nil & Nil \\
\hline & Severe & Nil & Nil & Nil & Nil \\
\hline \multirow{3}{*}{$33-36$} & Mild & 1 & 1 & 3 & 9 \\
\hline & Moderate & Nil & Nil & Nil & Nil \\
\hline & Severe & Nil & Nil & Nil & 1 \\
\hline \multirow{3}{*}{$>36$} & Mild & Nil & 1 & 2 & 7 \\
\hline & Moderate & Nil & 1 & Nil & 2 \\
\hline & Severe & Nil & Nil & Nil & 2 \\
\hline
\end{tabular}

Table 4: Distribution of cases according to severity of PIH at time of delivery.

\begin{tabular}{|l|llll|}
\hline \multirow{2}{*}{ Clinical characters } & Low platelet group & High risk group & Group D \\
\hline Mild & Group A & Group B & Group C & 11 \\
\hline Moderate & 1 & 1 & 3 & 2 \\
\hline Severe & Nil & 1 & Nil & 3 \\
\hline Total PIH present & Nil & Nil & Nil & $16(23.52 \%)$ \\
\hline PIH absent & $1(5.55 \%)$ & $2(13.33 \%)$ & $3(3.48 \%)$ & $68(76.48 \%)$ \\
\hline Total & $17(94.45 \%)$ & $13(86.67 \%)$ & $83(96.52 \%)$ & 84 \\
\hline
\end{tabular}

Total incidence of PIH is $10.8 \%$ in study group, [aspirin treated cases $(\mathrm{n}=104)$, placebo (99)]; Incidence of PIH in Aspirin treated group $=4 / 104 \times 100=3.8 \%$; Incidence of PIH in Placebo treated group $=18 / 99 \times 100=18.18 \%$.

Table 5: Comparison of studied groups as regard to albuminuria.

\begin{tabular}{|c|c|c|c|c|}
\hline \multirow{2}{*}{ GA in weeks } & \multicolumn{2}{|c|}{ Low platelet group } & \multicolumn{2}{|c|}{ High risk group } \\
\hline & Group A & Group B & Group C & Group D \\
\hline $28-32$ & Nil & Nil & Nil & Nil \\
\hline $33-36$ & Nil & 1 & Nil & 3 \\
\hline$>36$ & Nil & 2 & 3 & 7 \\
\hline Total & Nil & 3 & 3 & 10 \\
\hline
\end{tabular}

Total incidence of albuminuria is $7.88 \%$ in study group, [aspirin treated cases $(\mathrm{n}=104)$, placebo (99)]; incidence of albuminuria in aspirin treated group $=3 / 104 \times 100=2.88 \%$; incidence of albuminuria in placebo treated group $=13 / 99 \times 100=13.13 \%$. 
When comparing the distribution of pregnancy induce hypertension among various groups, Group A had 5.5\%, Group B had 13.3\%, Group C had 3.48\% and Group D had $23.52 \%$. Clearly the aspirin group had lesser incidence of PIH when compared to placebo group and this result was statistically significant in this study Table 4.

When study analysed the incidence of albuminuria in aspirin treated group it was found that only $2.88 \%$ had albuminuria and incidence of albuminuria in placebo treated group was $13.13 \%$. Hence the incidence of proteinuria in placebo group was high in comparison to aspirin treated group Table 5 .

\section{DISCUSSION}

The present study was conducted in the department of obstetrics and gynecology, SCB medical college and hospital, Cuttack, being a prospective RCT. In the present study, 240 cases were taken among the pregnant women visiting the ANC of department of obstetrics between the gestation of 13 to 28 weeks. Women with previous history of bleeding disorders were excluded from the study. These women were randomly divided into groups receiving aspirin $\mathrm{n}=104$, and not receiving aspirin $\mathrm{n}=$ 99. 37 patients could not be followed up to delivery in this study.

Figure 1 gives a picture of distribution of cases according to age in this study population. Maximum number of cases were in the age group of 21-25 years followed by 26-30 years. Least number of cases were above the age of 35 years. Which reflects early marriage and conception, contraceptive awareness has trickled into the society. ${ }^{6}$ However, high fertility and discontinued education after marriage remain the other facets of concern. ${ }^{7,8}$

Figure 2 and Table 1 studies about the habitation of pregnant women attending ANC clinic in study hospital and also the social status. Out of all the cases $73.3 \%$ belong to rural area and $26.7 \%$ cases belong to urban areas. This indicates the increased awareness regarding antenatal care among rural population. ${ }^{9}$ Among the cases taken up for the study $60 \%$ belong to middle class and $35 \%$ belong to low socioeconomic status. This being a government hospital and a tertiary care hospital caters to all social status of the society, however ANC although has good penetration in rural areas social factors also do reflect the number of foot falls to study hospital. ${ }^{10}$

Figure 3 indicates the distribution of cases as per risk factors. Maximum number of women were having history of hypertension or pre-eclampsia - eclampsia in previous pregnancy. ${ }^{11}$

Table 4, studies the comparison of severity of PIH as per gestation age. Out of 203 cases which could be followed up till delivery, 22 cases developed PIH. Hence the incidence of $\mathrm{PIH}$, in this study was $10.8 \%$, which is similar to that of Bangal et al, but more the national average of $7.8 \%$ out of the 22 cases, 3 developed severe $\mathrm{PIH}$, all of whom belonged to women having high risk factor for developing PIH but not treated with aspirin. ${ }^{12,13}$ None of the women treated with aspirin, developed severe PIH. Two cases belonging to placebo group developed mild PIH in 28-32 weeks of gestation. Overall, among high risk women $3.65 \%$ had developed PIH in aspirin treated group, which was substantially lower than the control group i.e. $23.5 \%$. the difference observed is statistically highly significant $\mathrm{p}$ value $<0.001$. this result was similar to results by Ramaiya et al, CLASP RCT, Cheng et al, and Imperiale et al. ${ }^{14-17}$

Table 5 shows that the incidence of albuminuria is relatively high in the control group. CLASP trial had showed albuminuria in non-aspirin treated patients at 9.6\%, whereas Rogers MS et al, had 8.5\%. However, both studies had relatively higher albuminuria in nonaspirin treated cases which is similar to this study. ${ }^{15,18}$

\section{CONCLUSION}

The present shows that low dose aspirin even as low as $60 \mathrm{mg}$ daily has a definite role in prevention of PIH in high risk women. Low dose aspirin reduces the incidence of PIH, as well as incidence of albuminuria in women at high risk of PIH. Low dose aspirin in pregnancy can be considered a safe drug without any deleterious side effects on mother or the fetus. Benefits of prevention of $\mathrm{PIH}$, justifies its administration in women at high-risk.

Funding: No funding sources Conflict of interest: None declared

Ethical approval: The study was approved by the Institutional Ethics Committee

\section{REFERENCES}

1. Osungbade KO, Ige OK. Public health perspectives of preeclampsia in developing countries: implication for health system strengthening. J Preg. 2011;2011:481095.

2. Rao KB. Report of maternal mortality committee, Federation of obstetrics and gynecology. Soci India. 1982:12.

3. Montgomery AL, Ram U, Kumar R, Jha P. Million death study collaborators. Maternal mortality in India: causes and healthcare service use based on a nationally representative survey. PLoS One. 2014;9(1):e83331.

4. Redman CWG. Current topic: pre-eclampsia and the placenta. Placenta. 1991;12:301-8.

5. Henderson JT, Whitlock EP, O'Connor E, Senger CA, Thompson JH, Rowland MG. Low-dose aspirin for the prevention of morbidity and mortality from preeclampsia: a systematic evidence review for the U.S. preventive services task force. Evide Synth. 2014;14-05207-EF-1. 
6. Aguayo Víctor M, Kajali P. Nutrition in adolescent girls in South Asia. BMJ. 2017;357:j1309.

7. International Institute for Population Sciences. National family health surveys, India. Key findings from NFHS-3. Mumbai: International Institute for Population Sciences; 2007. Available at: http://rchiips.org/nfhs/factsheet.shtml. Accessed 13 January 2020.

8. Mukhopadhyay P, Chaudhuri RN, Paul B. Hospitalbased perinatal outcomes and complications in teenage pregnancy in India. J Health Popul Nutr. 2010;28(5):494-500.

9. Britto, Catherin, Nisha. Awareness of Government Maternity Benefit Schemes among women attending antenatal clinic in a rural hospital in Karnataka, India. Inter J Current Res Acad Rev. 2015;3:137-43.

10. Dairo, Magbagbeola, Owoyokun, Kunle. Factors affecting the utilization of antenatal care services in Ibadan, Nigeria. Nigeria Benin J Postgrad Med. 2010;12:1.

11. Hernández-Díaz S, Toh S, Cnattingius S. Risk of pre-eclampsia in first and subsequent pregnancies: prospective cohort study. BMJ. 2009;338:b2255.

12. Bangal VB, Giri PA, Mahajan AS. Maternal and foetal outcome in pregnancy induced hypertension: a study from rural tertiary care teaching hospital in India. Int J Biomed Res. 2011;2:595-9.

13. Rastogi A, National Health Portal published in 2016, Govt. of India. Available at: https://www.nhp.gov.in/disease/gynaecology-andobstetrics/preeclampsia. Accessed on $13^{\text {th }}$ January 2020.

14. Ramaiya C, Mgaya HN. Low dose aspirin in prevention of pregnancy-induced hypertension in primigravidae at the Muhimbili Medical Center, Dar es Salaam. East Afr Med J. 1995;72:690-3.

15. CLASP: A randomised trial of low-dose aspirin for the prevention and treatment of pre-eclampsia among 9364 pregnant women. CLASP (Collaborative Lowdose Aspirin Study in Pregnancy) Collaborative Group. Lancet. 1994;343:619-29.

16. Cheng WW, Zhang ZJ. Low-dose aspirin preventing pregnancy induced hypertension (in Chinese) Zhonghua Fu Chan Ke Za Zhi. 1991;26:342-5.

17. Imperiale TF, Petrulis AS. A meta-analysis of lowdose aspirin for the prevention of pregnancy-induced hypertensive disease. JAMA. 1991;266(2):260-4.

18. Rogers MS, Fung HY, Hung CY. Calcium and lowdose aspirin prophylaxis in women at high risk of pregnancy-induced hypertension. Hypertens Preg. 1999; 18:165-72.

Cite this article as: Pradhan M, Kishore SV, Champatiray J. Effect of low dose aspirin on maternal outcome in women at risk for developing pregnancy induced hypertension. Int J Reprod Contracept Obstet Gynecol 2020;9:1590-5. 